\title{
The Effect of Isopropyl Alcohol and Chlorhexidine Gluconate on the Blood Glucose in Diabetic Patients Referring to the Emergency Department
}

Kazemi. M 1

Nezamzade. $\mathrm{M}^{2 *}$

Farsi. Z 3

1- MSC in Student of Emergency Nursing, Faculty of Nursing, Aja University of Medical Sciences, Tehran, Iran.

2- ( ${ }^{*}$ Corresponding Author) MSc in Nursing, Instructor, Maternal Newborn Department, Faculty of Nursing, Aja University of Medical Sciences, Tehran, Iran.

Email: Nezamzadeh_ maryam@yahoo.com

3- P.h.D in Nursing, Associate Professor, Research and Community Health Department, Faculty of Nursing, Aja University of Medical Sciences, Tehran, Iran.

\section{Abstract}

Introduction: Diabetes is a metabolic disorder that can cause considerable disability and mortality. The aim of controlling diabetes is to normalize blood glucose levels to reduce the progression of vascular and neurological complications. Blood glucose control and reassurance are essential for planning health care.

Objective: In the present study, the effect of local isopropyl alcohol and chlorhexidine gluconate disinfectants on blood glucose in diabetic patients referred to the emergency department was compared.

Materials and Methods: In this quasi-experimental study, 168 diabetic patients referred to the emergency department at 502 Hospital; their blood glucose levels were measured in three stages after local anesthetics with isopropyl alcohol, chlorhexidine gluconate and venous method. Then, the collected data were analyzed by descriptive statistical (percentage and frequency) and analytical ( $\mathrm{t}$-Test) methods to compare the mean of blood glucose using SPSS 21

Results: The results showed that the mean (219.72, 210.91 and 199.42) and standard deviation $(57.16,56.58$ and 57.29) of glucose level were measured with the glucometer after $70 \%$ applying isopropyl alcohol disinfection and $2 \%$ chlorhexidine gluconate and the venous blood test in the samples. Further, a capillary blood glucose measured is higher than that of glucose levels, and the mean of difference of chlorhexidine gluconate $70 \%$ and isopropyl alcohol was statistically significant by $\mathrm{t}$-Test $(\mathrm{P}=0.045)$.

Discussion and Conclusion: The results showed that there is a difference between capillary and venous test. Although the speed of operation in the emergency room is critical, clinical and therapeutic decisions require careful examination of the patient, and intravenous analysis will ultimately be useful to achieve an outcome. In emergencies, allowing the sampling position to dry the disinfection solutions can prevent false results which require the attention of nurses.

Keywords: Alcohol, Chlorhexidine, Clinical Trial Code, Diabetes, Local Anesthetics. 


\section{مقايسه تأثير ضدعفونى كنندهاى موضعى ايزويروييل الكل و كلر هكزيدين كلوكونات بر قند

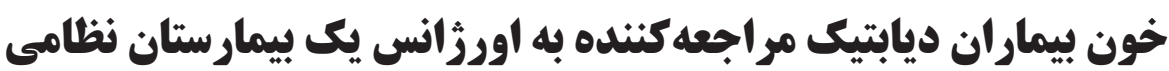

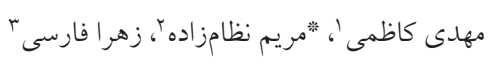

جكيده

مقدمه: ديابت يك بيمارى متابوليك است كه مىتواند باعث ناتوانى و مرگومير قابلملاحظهاى كردد. هدف اصلى از

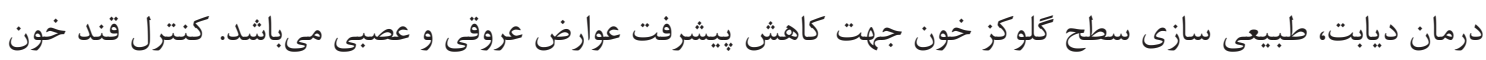

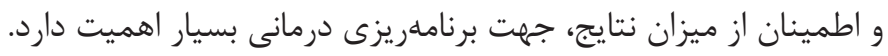

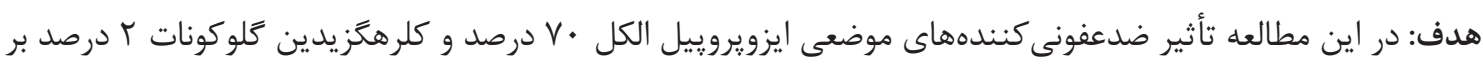

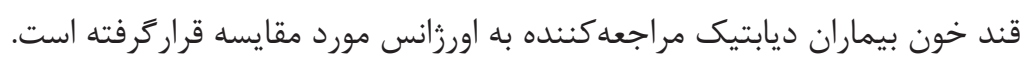

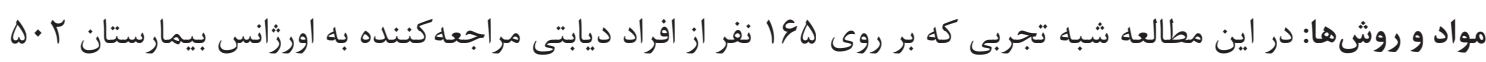

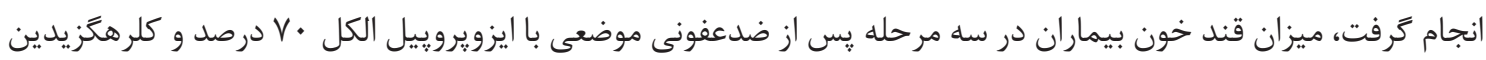

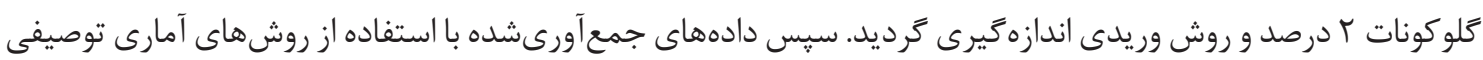

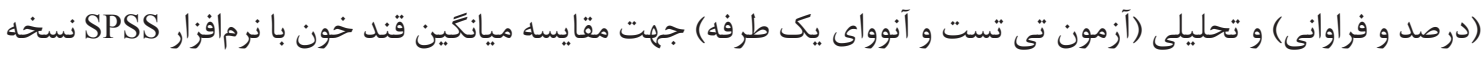

$$
\text { آم مورد تجزيه و تحليل قرار ترفتند. }
$$

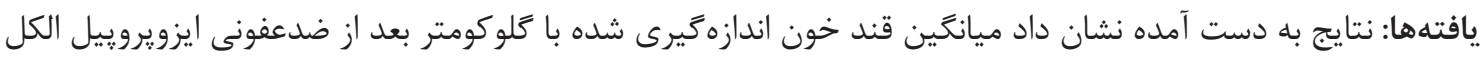

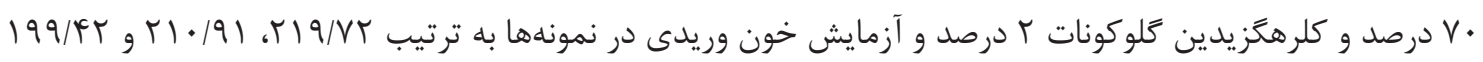

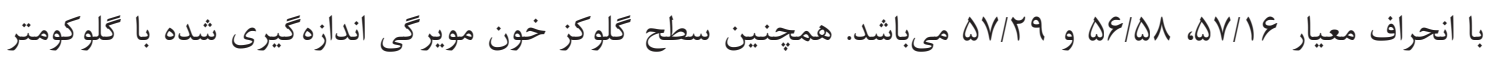

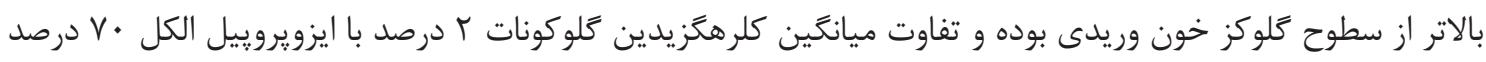

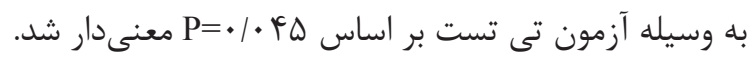

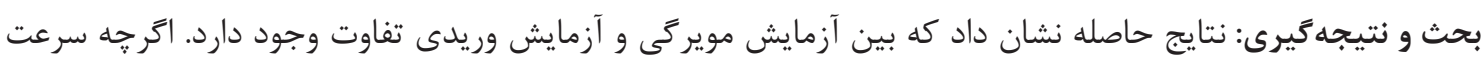

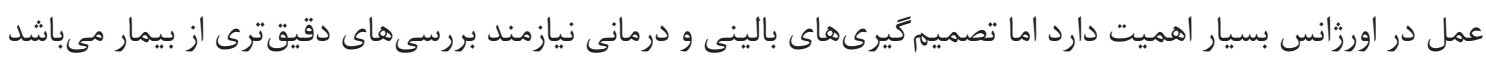

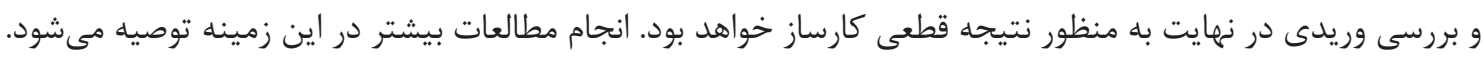

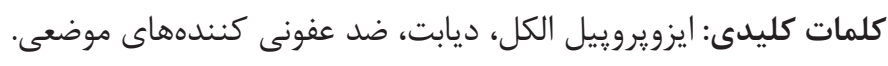


مويركى مىتواند از حساسيت و دقت بالاترى برخوردار باشد (9)؛

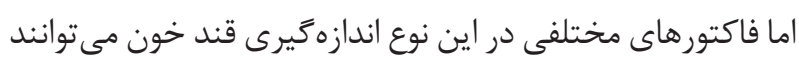

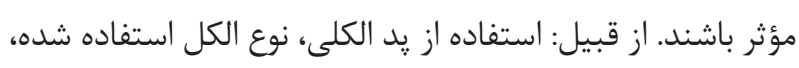
دوز مصرفى الكلى در تحقيقات بيانشده است (باس ا).

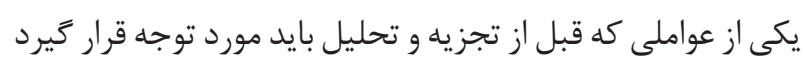
اين است كه يوست محل سوراخ قبل از نمونه كيرى خون بايد تميز باشد. تاكنون روش هاى مختلفى براى ضدعفونى كردن انخشت قبل

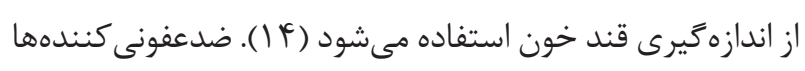
دستهاى از مواد هستند كه در سطح يوست، بدن (disinfectant)

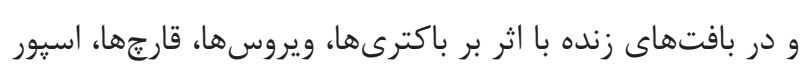
باكترىها (bacteria spur) و ساير ميكروار كانيسمهاى بيمارىزا،

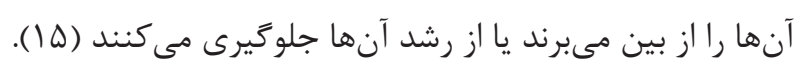

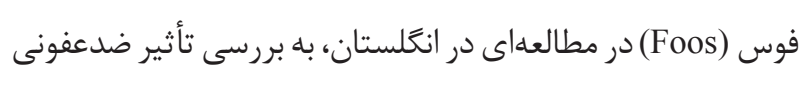
كنندهاى الكلى بر ميزان قند اندازمخيرى شده توسط حكلوكومتر

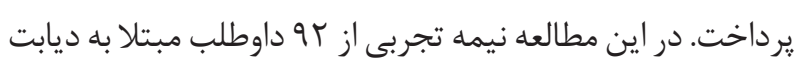

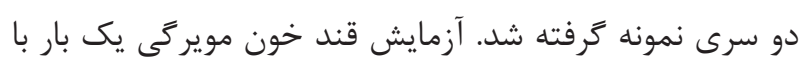

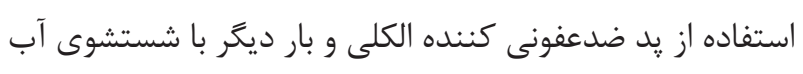
و صابون انجام كرفت. نتايج اين مطالعه نشان داد كه استفاده از

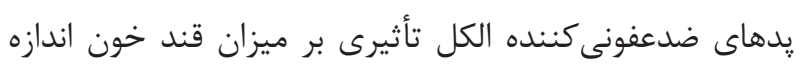

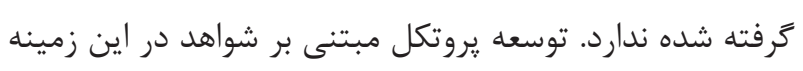

توصيه شد (9). اين ضدعفونى كننده به صورت منفرد در غلظتهاى ها • • تا أ درصد

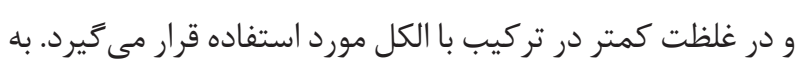

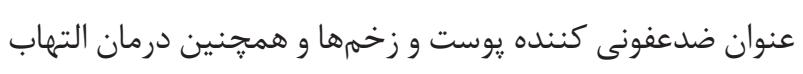
لثه در دهانشويهها نيز استفاده مىشود (م). ايزويروييل الكل مايعى است از خانواده الكلها است كه به طور گسترده به به عنوان حلال به خصوص براى حل كردن روغنها، حلال براى روكشها و... استفاده مىشود. اين ماده به دليل داشتن نقطه جوش نسبتاً

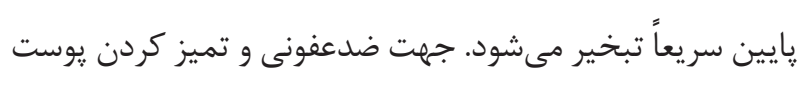

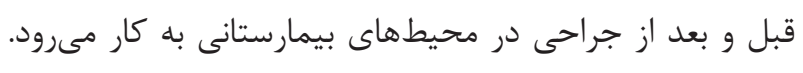

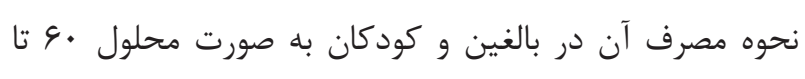

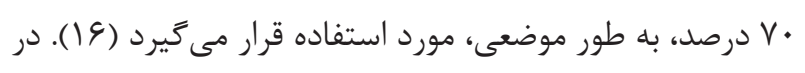

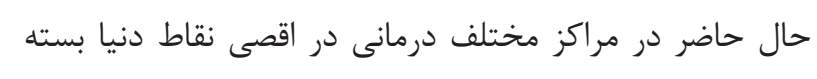

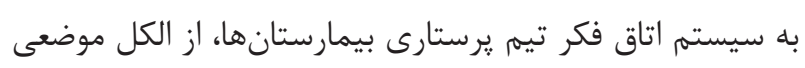

غير ديابتى هم سن و هم جنس آنها است (Y). بيمارى ديابت

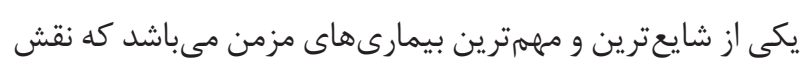

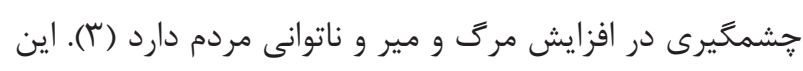

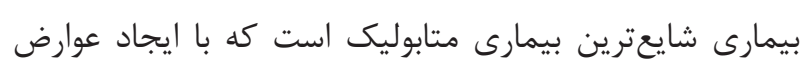
متعدد، كاهش كيفيت زندگى و افزايش مرك و مير مشكلات جدى مئري

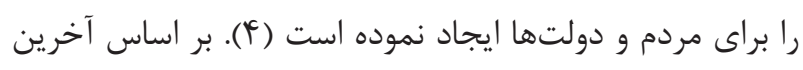

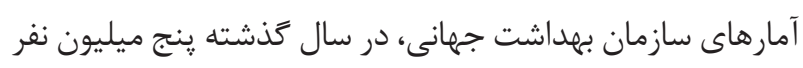

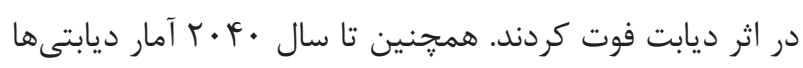

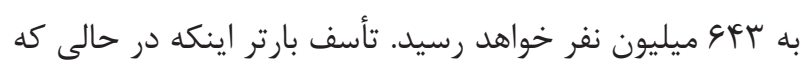

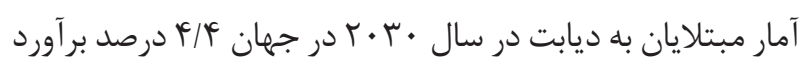

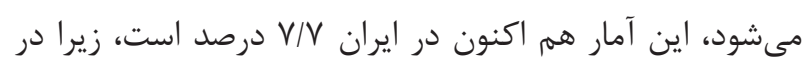

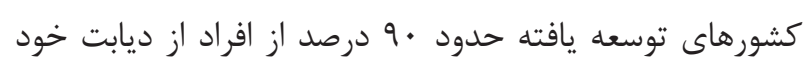

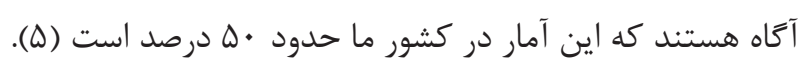

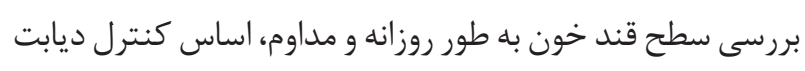
است و خود يايشى كلوكز خون توسط بيمار با دستخاه كلوكومتر

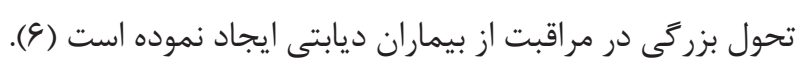

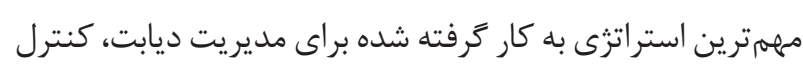

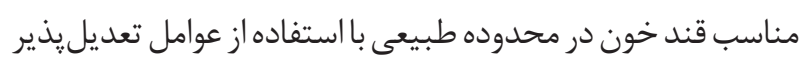
مىباشند (V). بيمارى هاى مزمن از جمله ديابت داراى منشأ بيجيده،

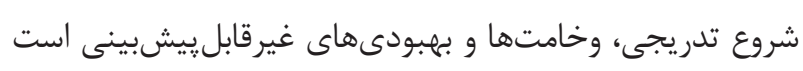

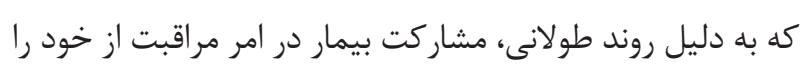

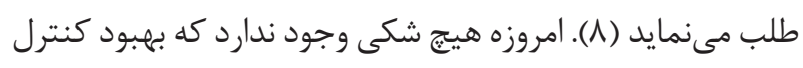
قند خون در بيماران ديابتى منجر به كاهش بروز عوارض مزمن فئن

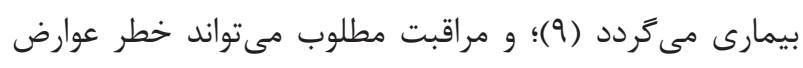

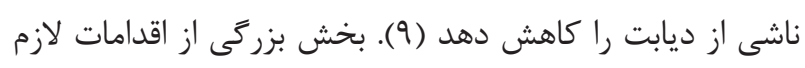

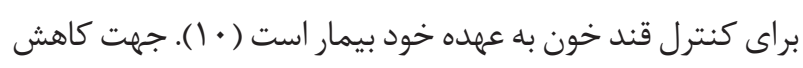

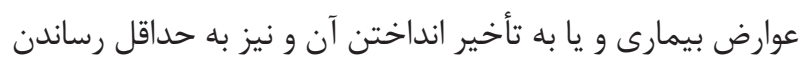

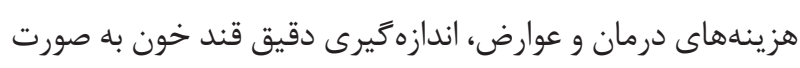
مرتب و منظم در بيماران ضرورت دارد (1) (1). كنترل موفقيت آميز

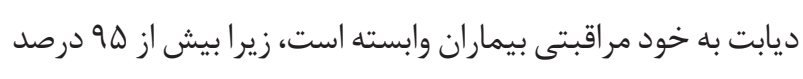

از مراقبتهاى ديابت به وسيله بيمار انجام مىشود (r) (I).

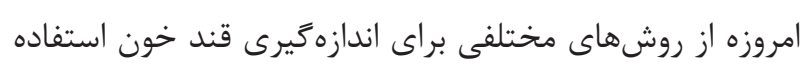
مىشود كه روشهاى وريدى و مويركى در اين بين از همه رايجتر

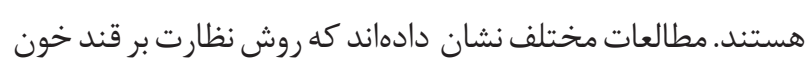


معيارهاى ورود به مطالعه شامل: تمايل به شركت در مطالعه،

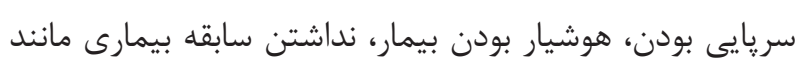

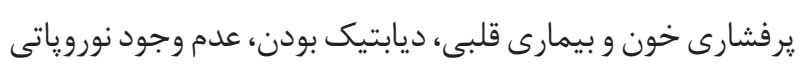

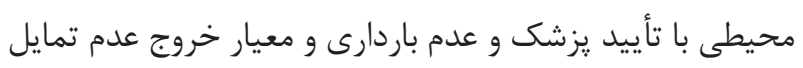

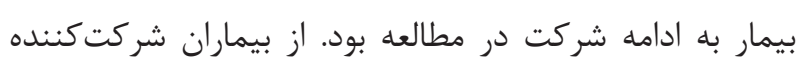

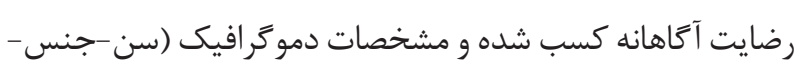

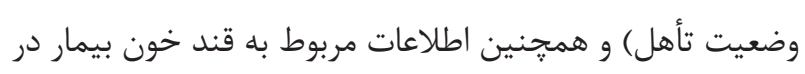

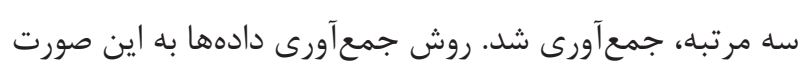

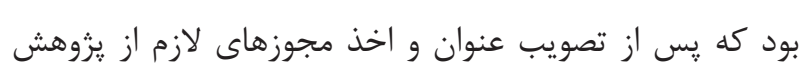

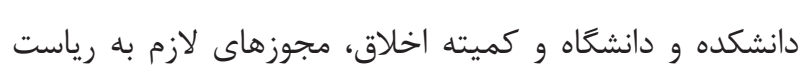

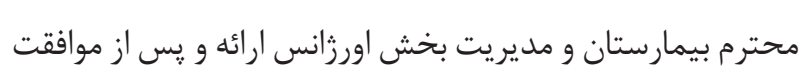

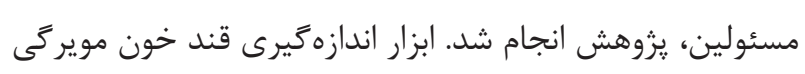
همه واحدهاى مورد يزوهش، از كلوكومتر يكسان دستَاه امبرور (Emperor)

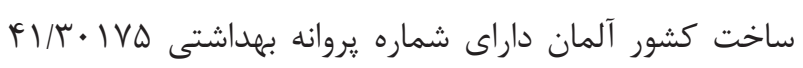

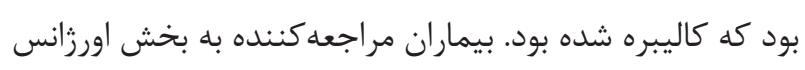

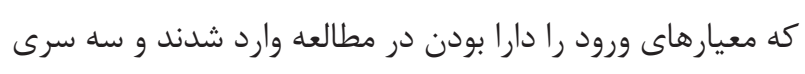

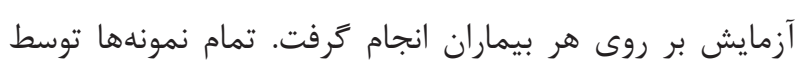
دانشجوى كارشناسى ارشد شاغل در اورزانس جهت يكسانسازى

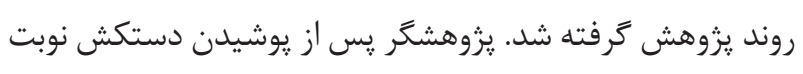
اول اندازهخيرى قند خون به صورت وريدى با پِد آغشته به ايزوييل

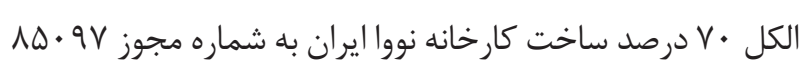

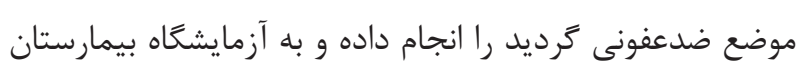

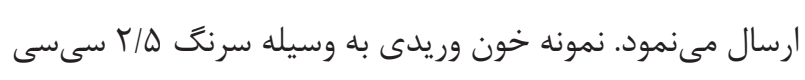

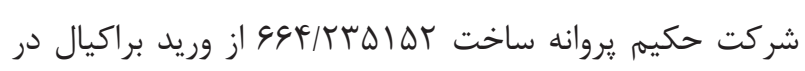
ناحيه آرنج دست غير غالب گرفته مىشد. لازم به ذكر است كه كه كرفتن نمونه خون وريدى به صورت روتين در اورزانس بيمارستان انجام مىشود و يس از جمع آورى با توجه به دماى محيط بله بلافاصله

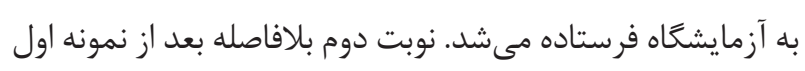

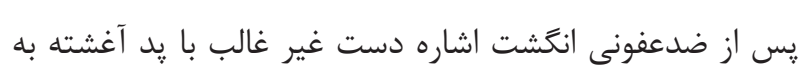
ايزوييل الكل • V درصد ساخت كارخانه نووا ايران به شماره مجوز

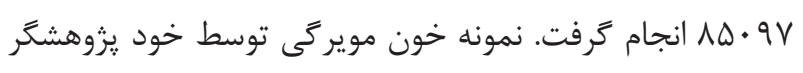
براى نوار تست (Strip Test) دستخاه اميرور ساخت كشور آلمان

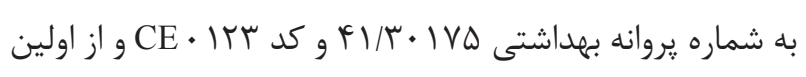

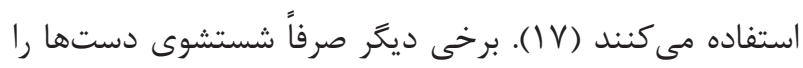

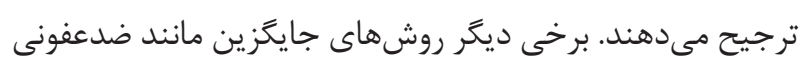

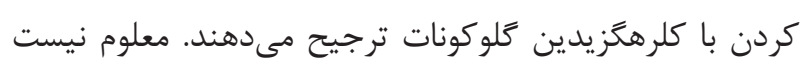

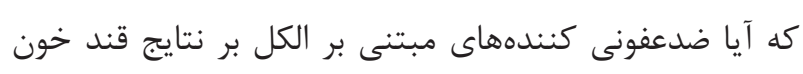

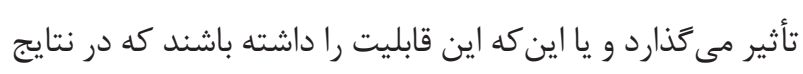
Fلوكومتر تداخل ايجاد كنند. فوس و ماهونى (Foos \& Mahooni)

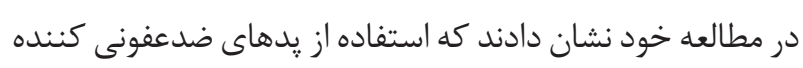

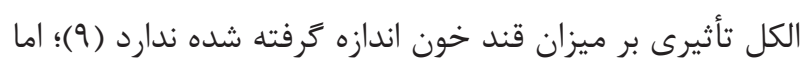
استين (Stin) نشان داد كه الكل مىتواند بر ميزان قند خون تأثير

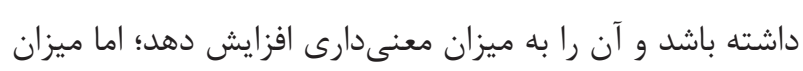

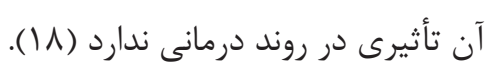

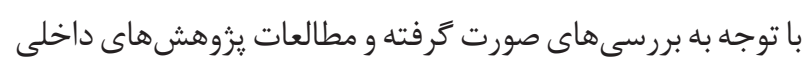
و خارجى مشخص كرديد كه تاكنون يزوهشى در خصوص مقايسه تأثير ضدعفونى كنندههاى موضعى ايزويروييل الكل و كلرهكَ يديد كردين

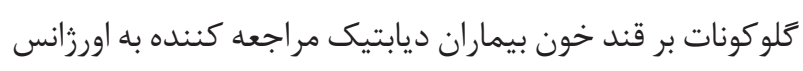

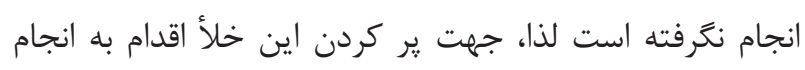
يزوهش حاضر گرفته شد تا در اين زمينه كمك شايانى به اورزانس بيمار ستان شده باشد.

\section{مواد و روشها}

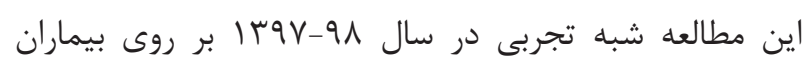
ديابتيك مراجعه كننده به اورزانس بيمارستان ك • له انجام كرفت.

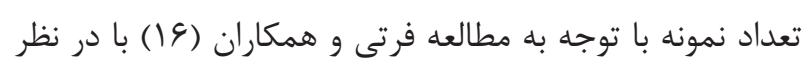

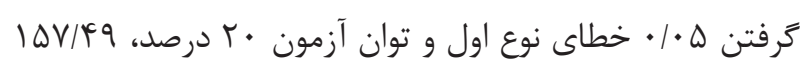

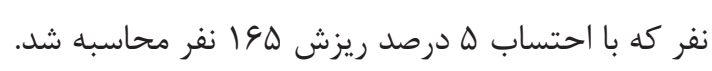

$$
\begin{aligned}
& n=\frac{\left(Z_{1-\frac{\alpha}{r}}+Z_{1-\beta}\right)^{r}\left(\delta l^{r}+\delta r^{r}\right)}{\left(i_{1}-i_{r}\right)^{r}} \\
& =\frac{(r / r r+\cdot / \Delta r)^{r}\left((r q / \cdot V)^{r}+(r q / \Delta \Delta)^{r}\right)}{(1 \cdot r / 11-11 r / \Delta \Delta)^{r}}=1 \Delta r / r q
\end{aligned}
$$

á $=\cdot / \cdot \Delta Z_{1-\frac{\alpha}{r}}=r / r r$

$\beta=\cdot / r \cdot Z_{1-\beta}=\cdot / \wedge \uparrow$ 
جدول ا - ميزان فراوانى نمونهها را بر اساس مشخصات دموكر افيك

\begin{tabular}{|c|c|c|c|}
\hline درصد & فراوانى & دمو & 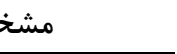 \\
\hline $99 / V$ & 110 & مرد & \multirow{2}{*}{ جنسيت } \\
\hline$r \cdot r$ & $\Delta \cdot$ & 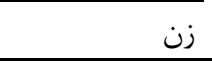 & \\
\hline $1 \cdot / \pi$ & IV & •r-r.r سال & \multirow{4}{*}{ سن } \\
\hline $1 \cdot / r$ & IV & 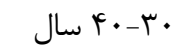 & \\
\hline $1 \cdot \pi$ & IV & 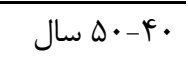 & \\
\hline $99 / \cdot 9$ & 114 & •ه سال به بالا & \\
\hline$\Lambda 1 / 1$ & 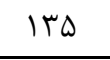 & دارد & \multirow{2}{*}{ سابقه بيمارى } \\
\hline $11 / r$ & $r$. & ندارد & \\
\hline $1 \cdots$ & 190 & لموع & \\
\hline
\end{tabular}

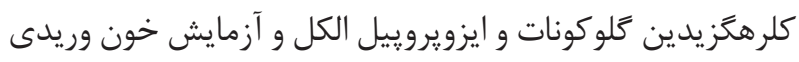

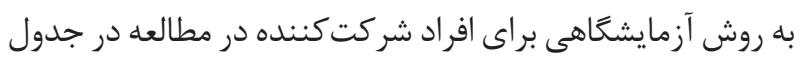
شماره r نشان داده شده است.

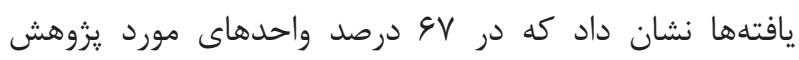
ميزان قند خون اندازهيرى شده با كلوكومتر بعد از ضدعفونى لئى

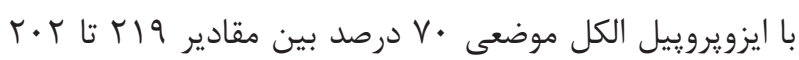

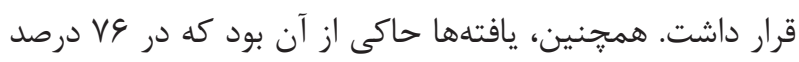

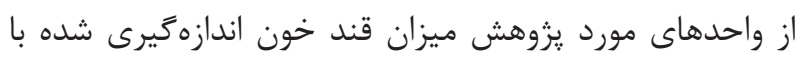

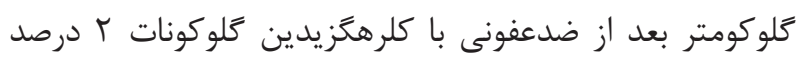

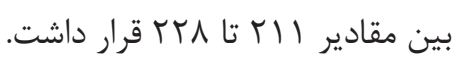
آزمون تى مستقل نشان داد كه ميانكَين قند خون گَروه كلرهكَ يدين

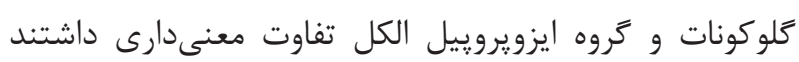

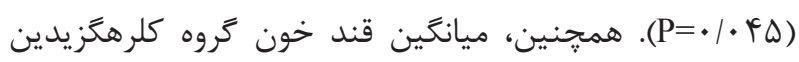

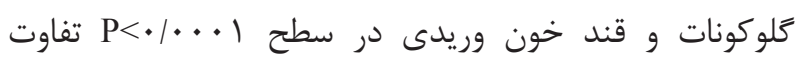

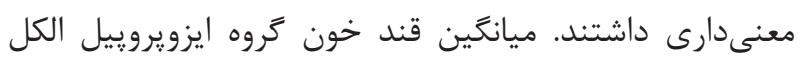

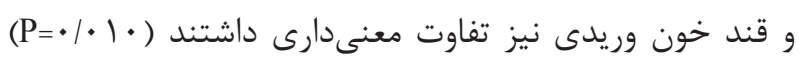

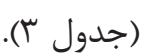

قطره خون انخَشت اشاره يس از هايين نحَه داشتن دست و بدون

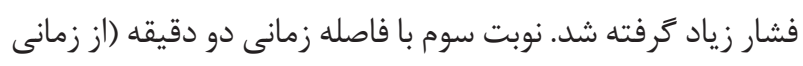

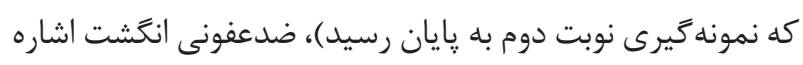

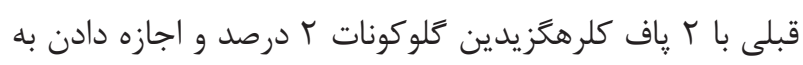
انگشت اشاره براى خشك شدن و نمونه خون مويرگى براى نو نوار

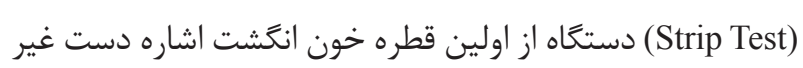

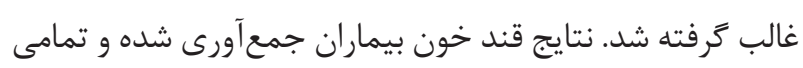
نتايج با نمونه وريدى مقايسه شد. اخذ معرفىنامه از معاونت تحقيقات و فناورى دانشعاه علوم

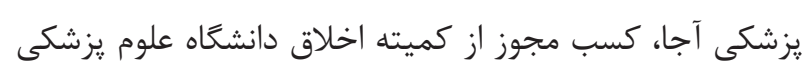

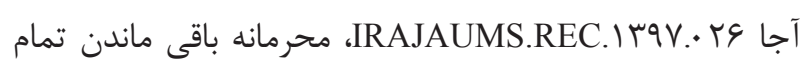

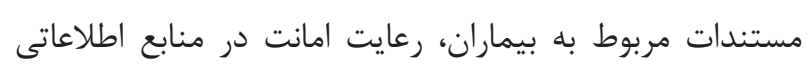

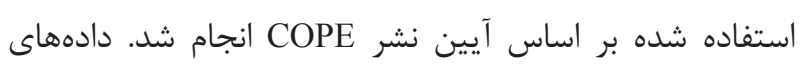

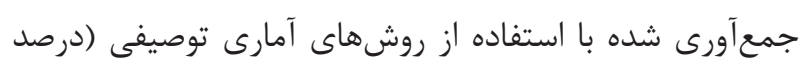

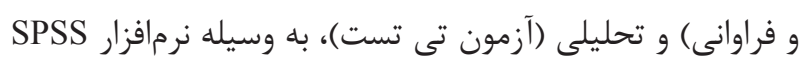

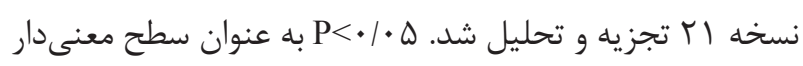
آمارى در نظر كرفته شد.

\section{يافتهها}

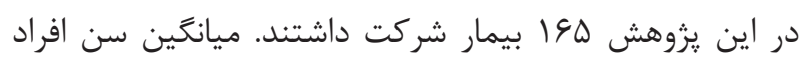

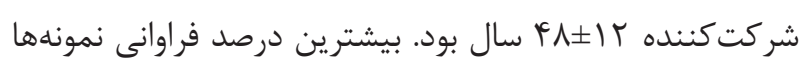

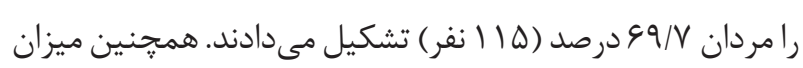

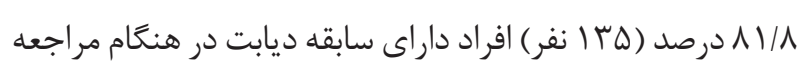
قند بالاى حد نرمال داشتند.

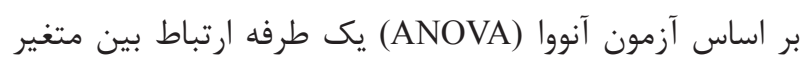

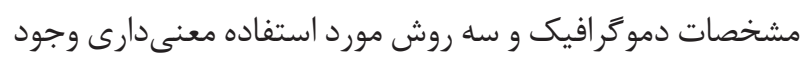
ندارد. ميانگين قند خون اندازهخيرى شده با كلوكومتر بعد از ضدعفونى

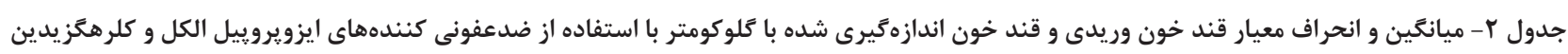
كلوكونات موضعى در واحدهاى مورد يثوهش

\begin{tabular}{|c|c|c|c|c|}
\hline انحراف معيار & ميانغين & بيشترين مقدار & كمترين مقدار & متغيرها \\
\hline$\Delta \varphi / \Delta \Lambda$ & $r 19 / V r$ & r६६ & ITY & كلوكومتر (كلرهكَزيدين كلوكونات) \\
\hline$\Delta V / 19$ & $(1 \cdot / 91$ & rvq & 11. & كلوكومتر (ايزويروييل الكل) \\
\hline$\Delta V / T q$ & $199 / 4 T$ & $r \cdot r$ & 11. & وريدى (آزمايشگاه) \\
\hline
\end{tabular}




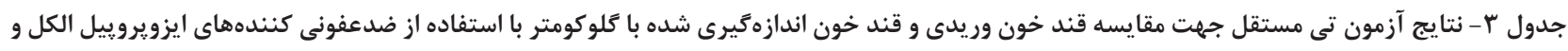

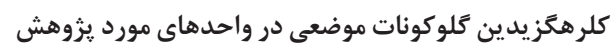

\begin{tabular}{|c|c|c|c|c|c|c|}
\hline \multicolumn{2}{|c|}{ فاصله اطمينان } & \multirow{2}{*}{ اختلاف ميانغين } & \multirow{2}{*}{ سطح معنىدارى } & \multirow{2}{*}{ درجه آزادى } & \multirow{2}{*}{ مقدار آماره t } & \multirow{2}{*}{ 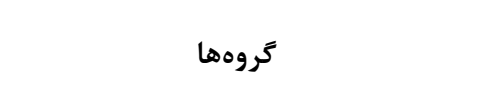 } \\
\hline سطح بالايى & سطح پايينى & & & & & \\
\hline IV/Fra & $\cdot / 198$ & $N / \Lambda) 9$ & $\cdot / \cdot 4 \Delta$ & 194 & $5 / .19$ & كلرهكًزيدين كلوكونات با ايزويروييل الكل \\
\hline TN/QT & II/GAV & $r \cdot / r \cdot \varphi$ & $<\cdot 1 \cdot \cdots 1$ & 194 & $F|q \Delta|$ & كلرهكَزيدين كلوكونات با قند خون وريدى \\
\hline$r \cdot / r$. & T/VA & $11 / 499$ & $.1 \cdot 1$. & 194 & $r / 9 \cdot V$ & ايزويروييل • V٪ با قند خون وريدى \\
\hline
\end{tabular}

اندازهگيرى شده با كلوكومتر و در زمان استفاده از ايزويروپيل الكل موضعى • V درصد و قند خون وريدى در بيماران مراجعه

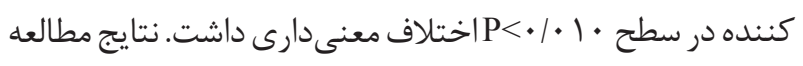
سرلتى و همكاران (Tr) نشان دادند دقت دو دستخاه مورد مطالعه

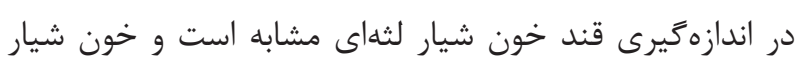

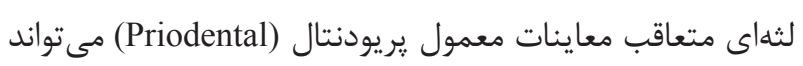
وسيله مناسبى براى تشخيص ديابت توسط كلوكومتر باشد، ضمن من رئن

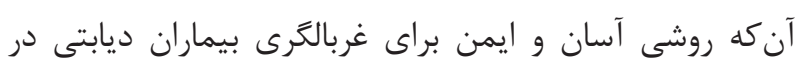

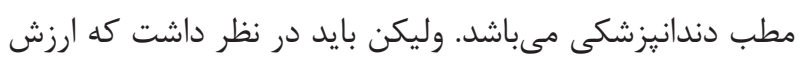
ريشينى منفى تكنيك GCBG (تشخيص ديابت به روشهاى

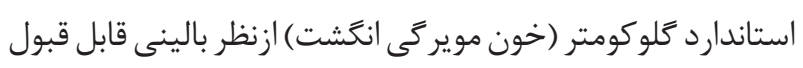

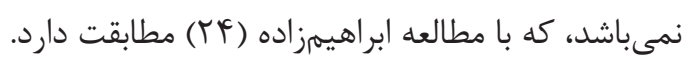

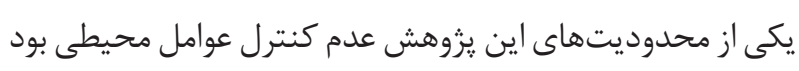

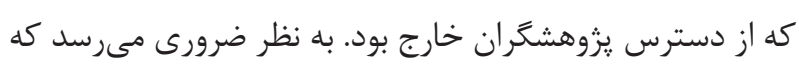

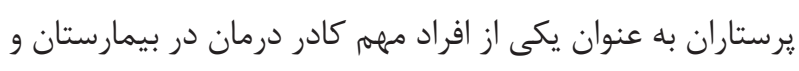

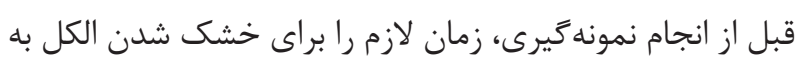

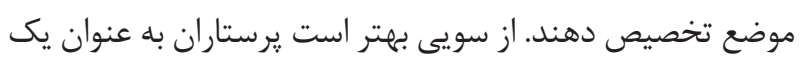

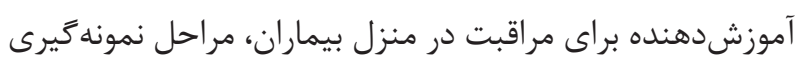
را به شكل صحيح به بيماران آموزش دهند.

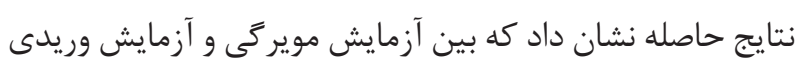

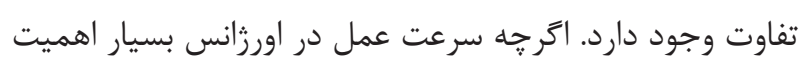

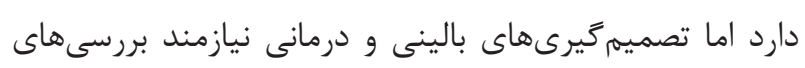

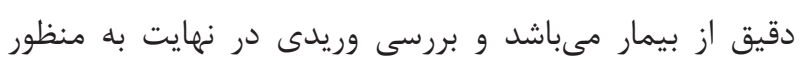

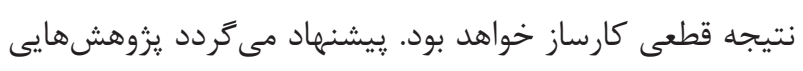

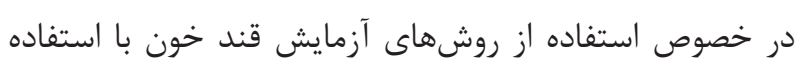

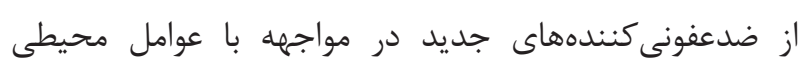

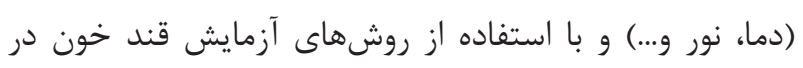

\section{بحث و نتيجه كيرى}

اين مطالعه با هدف مقايسه تأثير ضدعفونى كنندههاى موضعى

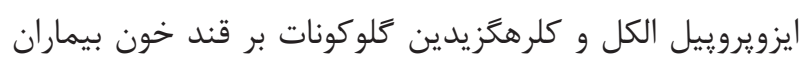
ديابتيك مراجعه كننده به اورزانس يك بيمارستان نظامى كين انجام

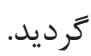
نتايج حاصل از تعيين ميزان قند خون اندازهخيرى شده با خلو كومتر

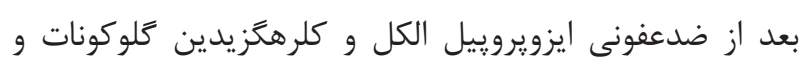

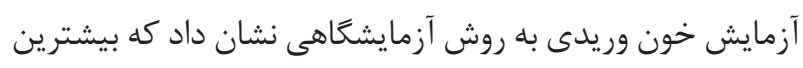

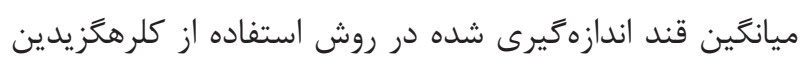

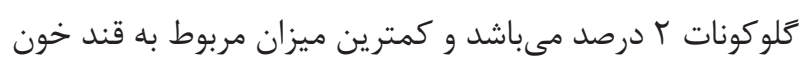

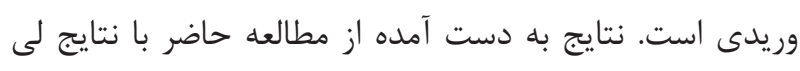

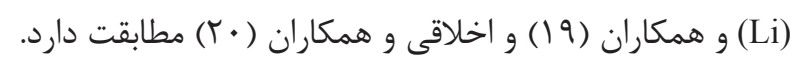

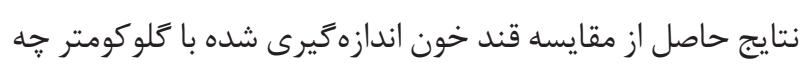

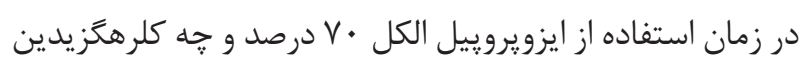

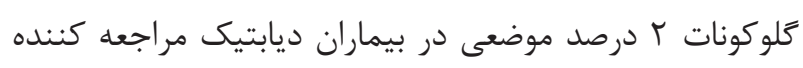

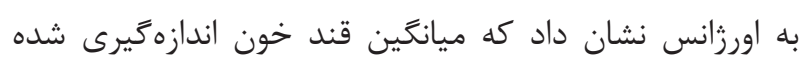

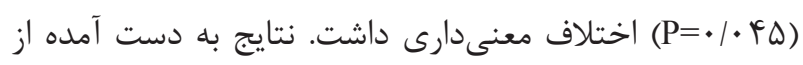

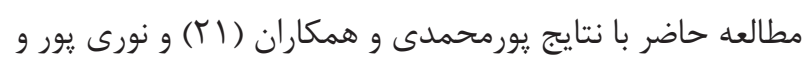

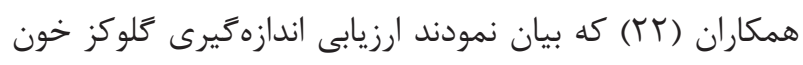

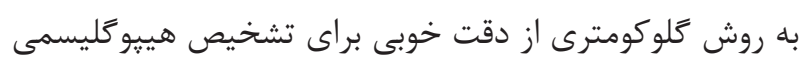
در نوزادان يرداختند، مطابقت دارد.

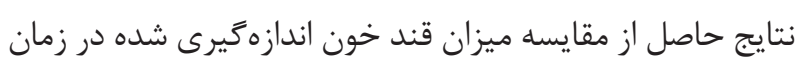

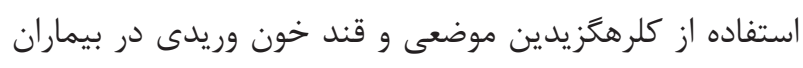

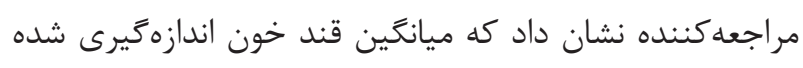

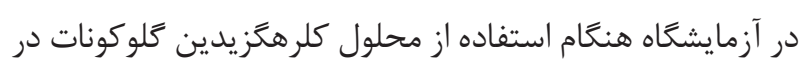

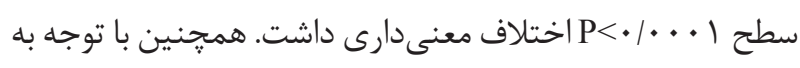

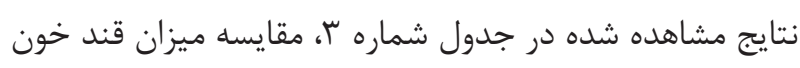




$$
\text { در يزوهش، مديران و مسئولين محترم دانشكده يرستارى و معاونت }
$$

\section{تضاد منافع}

بدينوسيله نويسندكان تصريح مىنمايند كه هيجزت

$$
\text { منافعى در خصوص مطالعه حاضر وجود ندارد. }
$$

\section{References}

1- American Diabetes A. 14. Diabetes care in the hospital: Standards of Medical Care in Diabetes-2018. Diabetes Care. 2018;41(Suppl 1):S144-S51. DOI: 10.2337/dc18-S014 PMID: 29222385

2- Petlevski R, Hadzija M, Slijepcevic M, Juretic D. Effect of 'antidiabetis' herbal preparation on serum glucose and fructosamine in NOD mice. J Ethnopharmacol. 2001;75(2-3):1814. PMID: 11297848

3- Edelman D, Olsen MK, Dudley TK, Harris AC, Oddone EZ. Utility of hemoglobin A1c in predicting diabetes risk. J Gen Intern Med. 2004;19(12):1175-80. DOI: 10.1111/j.1525-1497.2004.40178.x PMID: 15610327

4- Grant RW, Buse JB, Meigs JB. Quality of diabetes care in US academic medical centers: low rates of medical regimen change. Diabetes care. 2005;28(2):337-442.

5- Iranparvar Alamdari M, Ghorbani Behrooz H, Yazdanbood A, Amini Sani N, Islam panah S, Shokrabadi M. [Quality of Care in 100 Diabetic Patients in a Diabetes Clinic in Ardabil]. J Ardabil Univ Med Sci. 2012;12(3):239-47

6- Vinita D, Vaishali J, Anjoo A, Amita P, Sushma P, Agarwal C. Glucometer screening of gestational diabetes. J Obstetrics \& Gynecology of India. 2006;56(6):499-501.

7- Rheney C, Kirk J. Performance of three blood glucose meters. Annals of Pharmacotherapy. 2000;34(3):317-21.

8- Parker RC, Rapley JW, Isley W, Spencer P, Killoy WJ. Gingival crevicular blood for assessment of blood glucose in diabetic patients. J Periodontol. 1993;64(7):666-72. DOI: 10.1902/ jop.1993.64.7.666 PMID: 8366416

9- Foos J. The effect of alcohol prep pads and blood drop number on capillary blood glucose values. University of New Hampshir University of New Hampshire Scholars' Repository. 2017.

10- Kasper D, Braunwald E, Fauci A, Hauser S, Longo D, Jameson J. Harrison's principles of internal Medicine. 16thed ed. New York: McGraw-Hill; 2007.

11- Newman M, Takie H, Carrenza F. Clinical periodontology. 9th ed. Philadelphia: W.B. Saunders Co; 2002.

12- Raiff BR, Dallery J. Internet-based contingency management to improve adherence with blood glucose testing recommendations for teens with type 1 diabetes. J Appl Behav Anal. 2010;43(3):48791. DOI: 10.1901/jaba.2010.43-487 PMID: 21358907

$$
\text { مواجهاه با عوامل مربوط به بيماران (نوع تغذيه، زمان آزمايش و...) }
$$

تشكر و قدردانى

اين مقاله برگرفته از ياياننامه كارشناسى ارشد رشته يرستارى اورزانس مىباشد كه در دانشعاه علوم يزشكى آجا در تاريخ |

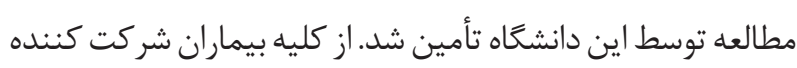

13- Fallah S, Rostamzadeh S. [Success of the Family Practice Plan in Diabetes Control]. J Health \& Hygiene. 2016;7(4):417-24

14- Fauci B, Kasper H, Longo J, Loscalzo. Harrison principal of internal medicine 17th ed: Mc graw Hill 2012

15- Beikler T, Kuczek A, Petersilka G, Flemmig TF. In-dental-office screening for diabetes mellitus using gingival crevicular blood. J Clin Periodontol. 2002;29(3):216-8. PMID: 11940140

16- Ruef C. Peripheral intravenous catheters-to change or not to change? Infection. 2004;32(1):1-.

17- Matheson GO, Klugl M, Engebretsen L, Bendiksen F, Blair $\mathrm{SN}$, Borjesson $\mathrm{M}$, et al. Prevention and management of noncommunicable disease: The IOC Consensus Statement, Lausanne 2013. Clin J Sport Med. 2013;23(6):419-29. DOI: 10.1097/JSM.0000000000000038 PMID: 24169298

18- Stein C. The effects of two differing techniques on the accuracy of reagent strip blood glucose testing. Health SA Gesondheid. 2007;12(3):17-25.

19- Li M, Wang X, Shan Z. Deciding between using the first or second drop of blood for the self monitoring of blood glucose. Primary Care Diabetes. 2014;8(4):365-9.

20- Akhlaghi F, Shakeri MT, Saboni N. Comparison of venous blood glucose and capillary blood glucose in the screening of gestational diabetes. Med J Mashhad Univ Med Scie. 2016;59(4):251-60.

21- Poormohamadi M, Farsi Z, Rajai N. [The Effect of $2 \%$ Chlorhexidine Gluconate Solution on Prevention of Phlebitis Related to Peripheral Venous Catheter in Patients Hospitalized in Cardiac Care Units of a Military Hospital]. Military Caring Sciences 2017;4(1):19-29.

22- Nooripoor S, Ghorbani R, Azizzadeh F, Danai N, Yazdiha M. [Evaluating the blood glucose measured via glucometry in diagnosis of hypoglycemia in neonates]. Koomesh 2012;13(4):440-4.

23- Sarlati F, Vallaei N, Pakmehr E, Khoshroo K. [Comparison of efficacy of two glucometers (Accuchek and Elite) in diagnosis of diabetes using bleeding on probing]. Research in Medicine. 2010;33(4):228-34.

24- EbrahimZadeh M. A comparison of blood glucose level measured by standard laboratory procedure with that of five glucometer devices in patients with diabetes mellitus. J Res Develop in Nurs \& Midwife. 2013;10(2):63-8. 